\title{
PERANAN INOVASI SEBAGAI MEDIATOR TERHADAP KINERJA USAHA KECIL MENENGAH ASESORIS GAWAI DI ROXY MAS JAKARTA
}

\author{
Michael Christian' ${ }^{1}$, Merisa ${ }^{2)}$ \\ ${ }^{1)}$ 2)Manajemen, Universitas Bunda Mulia \\ Diterima 10 Februari 2020 / Disetujui 30 Maret 2020
}

\begin{abstract}
Business performance is influenced by several factors, one of which is the innovation of sales ideas. Previous studies also explain the role of innovation in determining the performance of the business being undertaken. Some researches on the role of innovation in determining business performance emphasizes aspects of top management involvement, resources, existing technological capabilities and organizational culture. This research aims to analyse the determinants of business performance factors, especially on the role of innovation as a mediating factor. This research is quantitative using Partial Least Square (PLS)-Structural Equation Modelling (SEM) models. The results of this study explain that Innovation and Management Capability do not have an influence on business performance in the SME accessories gadget at ITC Roxy Mas. However, entrepreneurial orientation has an influence on business performance in the gadget accessories SMEs at ITC Roxy Mas. Furthermore, entrepreneurial orientation and management ability have an influence on innovation in the gadget accessories SMEs at ITC Roxy Mas. The results of the indirect effect explain the entrepreneurial orientation and management capabilities that are mediated by innovation do not have an influence on business performance in the gadget accessories SMEs at ITC Roxy Mas.
\end{abstract}

Keywords: Business performance, SMEs, innovation, entrepreneurship

\begin{abstract}
ABSTRAK
Keberhasilan usaha dipengaruhi oleh beberapa faktor, salah satunya adanya inovasi ide penjualan. Penelitianpenelitian terdahulu juga menjelaskan peranan inovasi dalam menentukan keberhasilan usaha yang dijalani. Beberapa penelitian mengenai peranan inovasi dalam menentukan kinerja usaha menekankan pada aspek keterlibatan manajemen puncak, sumber daya yang dimiliki, kemampuan teknologi yang ada dan budaya organisasi. Tujuan ini bertujuan untuk menganalisis determinan pada faktor kinerja usaha khususnya pada peranan inovasi sebagai faktor pemediasi. Penelitian ini bersifat deskriptif kuantitatif dengan menggunakan Partial Least Square (PLS) untuk model Structural Equation Modelling (SEM). Hasil penelitian ini menjelaskan bahwa Inovasi dan Kemampuan Manajemen tidak mempunyai pengaruh terhadap kinerja bisnis pada UKM asesoris gawai di ITC Roxy Mas. Namun demikian Orientasi kewirausahaan mempunyai pengaruh terhadap kinerja bisnis pada UKM asesoris gawai di ITC Roxy Mas. Selanjutnya, Orientasi kewirausahaan dan Kemampuan Manajemen mempunyai pengaruh terhadap inovasi pada UKM asesoris gawai di ITC Roxy Mas. Hasil efek tidak langsung menjelaskan Orientasi kewirausahaan dan Kemampuan Manajemen yang dimediasi inovasi tidak mempunyai pengaruh terhadap kinerja bisnis pada UKM asesoris gawai di ITC Roxy Mas.
\end{abstract}

Kata Kunci: Kinerja bisnis, UKM, inovasi, kewirausahaan

Corresponding Author: mchristian@bundamulia.ac.id

\section{PENDAHULUAN}

Berdasarkan data dari International Data Corporation (IDC) menyatakan bahwa pada periode 2016-2018 hanya 3 merek gawai yang konsisten berada dalam 5 besar untuk pangsa pasar di Indonesia, yaitu Samsung, OPPO dan Advan. Perusahaan jasa intelijen pasar dan kosultasi untuk teknologi informasi tersebut juga menyatakan bahwa Xiaomi muncul sebagai pemain baru yang berhasil 
masuk dalam 5 besar untuk pangsa pasar di Indonesia tahun 2018. Hal ini menjelaskan bahwa dalam sektor industri penjualan gawai, merek-merek populer tidak selamanya dapat mempertahankan eksistensinya dalam meraih pangsa pasar besar di Indonesia. Daya beli dan selera masyarakat yang cenderung berubah mengakibatkan naik turunnya penjualan suatu merek gawai.

Tabel 1. Pangsa Pasar Terbesar Merek Gawai di Indonesia 2016-2018

\begin{tabular}{llll}
\hline \multirow{2}{*}{ Merek } & \multicolumn{3}{c}{ Market Share } \\
\cline { 2 - 4 } & $\mathbf{2 0 1 6}$ & $\mathbf{2 0 1 7}$ & $\mathbf{2 0 1 8}$ \\
\hline Samsung & $28,8 \%$ & $31,8 \%$ & $27 \%$ \\
\hline Xiaomi & $*$ & $*$ & $25 \%$ \\
\hline Oppo & $16,6 \%$ & $22,9 \%$ & $18 \%$ \\
\hline Vivo & $*$ & $6,0 \%$ & $9 \%$ \\
\hline Advan & $6,8 \%$ & $7,7 \%$ & $6 \%$ \\
\hline Asus & $10,5 \%$ & $6,5 \%$ & $*$ \\
\hline Lenovo & $5,6 \%$ & $*$ & $*$
\end{tabular}

Sumber: IDC (2018)

Berbicara mengenai usaha penjualan gawai di Indonesi, terdapat satu usaha yang berhungan erat dengan usaha tersebut yaitu usaha penjualan asesoris gawai. Usaha ini tidak terlepas dari penjualan gawai di pusat-pusat perbelanjaan, salah satunya di ITC Roxy Mas Jakarta. Keberhasilan usaha dipengaruhi oleh beberapa faktor, salah satunya adanya inovasi ide dalam menjual seperti menggunakan teknologi daring dalam penjualannya (Mamduh, 2018). Inovasi dapat diartikan sebagai tindakan sejauh mana perusahaan atau usaha terlibat dalam mencari ide baru, eksperimen, kebaruan, dan kreativitas pada produk atau layanan yang akan diberikan (Lumpkin \& Dess, 1996). Inovasi tidak hanya berkaitan dengan kreativitas menghasilkan produk dan jasa, namun juga yang dapat membuat proses teknologi baru (Dhliwayo, 2014). Proses kreativitas dalam menciptakan inovasi tersebut berada dalam kendali manajemen (Prajogo, 2015) yang mana sebenarnya dapat membantu perusahaan untuk bertahan dan bersaing dalam ketidakstabilan persaingan usaha yang ada (Calantone, Cavusgil, \& Zhao, 2002). Inovasi juga dipandang dapat memberikan efektivitas dengan mempertimbangkan pengaruh

\footnotetext{
${ }^{1}$ Korespondensi Penulis: michaelchristianid@ gmail.com
}

lingkungan sekitar untuk bersaing (Tsai \& Yang, 2013; Jansen, Van Den Bosch, \& Volberda, 2006; Katila \& Shane, 2005). Penelitian-penelitian terdahulu juga menjelaskan peranan inovasi dalam menentukan keberhasilan usaha yang dijalani. Beberapa penelitian mengenai peranan inovasi dalam menentukan kinerja usaha menekankan pada aspek keterlibatan manajemen puncak, sumber daya yang dimiliki, kemampuan teknologi yang ada dan budaya organisasi (Oke, Projogo, \& Jayaram, 2013; Murat Ar \& Baki, 2011; Herzog \& Leker, 2010; Arago'n-Correa, Garci'a-Morales, \& Cordo'n-Pozo, 2007; dan Bhattacharya \& Bloch, 2004).

Caseiro \& Coelho (2018) menjelaskan bahwa inovasi pada produk membentuk orientasi kewirausahaan. Lebih lanjut inovasi dapat berperan sebagai penggerak kedinamisan dan persaingan bagi produk dan proses bisnis (Jayaram, Oke, \& Prajogo, 2014 dan Damanpour, 2010). Inovasi pada produk dan proses dipandang memiliki nilai strategis yang signifikan untuk mencapai keunggulan kompetitif (Jiang, Waller, \& Cai, 2013; Shu, Page, Gao, \& Jiang, 2012 dan Goedhuys \& Veugelers, 2012). Tindakan inovasi pada perusahaan tidak jarang disebabkan karena ada 
beberapa faktor eksternal seperti strategi yang dijalankan pesaing, selera pasar, dan regulasi atau kebijakan pemerintah (Prajogo, 2015; Yalabik \& Fairchild, 2011; Tao, Garnsey, Probert, \& Ridgman, 2010; Corrocher \& Zirulia, 2010). Selain inovasi, faktor tindakan proaktif dan keberanian dalam mengambil risiko menjadi pembentuk dalam menentukan orientasi kewirasausahaan. Hal ini sejalan juga dengan penelitian yang dilakukan oleh (Herath \& Rosli, 2014; Covin \& Miller, 2014; dan Wiklund \& Shepherd, 2003).

Namun demikian, beberapa penelitian justru tidak menyatakan bahwa inovasi memiliki pengaruh terhadap kinerja bisnis. Huang \& Rice (2009) menyatakan bahwa inovasi tidak memiliki pengaruh terhadap kinerja bisnis dan faktor internal dan eksternal. Selanjutnya Tuan, Nhan, Giang, \& Ngoc, (2016) menyatakan bahwa inovasi pada produk berdampak tidak signifikan terhadap kinerja inovatif, inovasi pada proses, organisasi, dan pemasaran memiliki pengaruh yang lebih dominan pada kinerja perusahaan. Di satu sisi penelitian Atalay, Anafarta, \& Sarvan (2013) menjelaskan bahwa inovasi pada teknologi produk dan proses memiliki dampak signifikan dan positif pada kinerja perusahaan, tetapi di sisi lain tidak ada bukti pada hubungan yang signifikan dan positif antara inovasi nonteknologi (inovasi organisasi dan pemasaran) dan kinerja perusahaan. Hasil sejalan juga menjelaskan bahwa inovasi tidak selalu mengarah pada pertumbuhan perusahaan (Alex Coad et al., 2014; Audretsch, Coad, \& Segara, 2014 dan A Coad \& Rao, 2008). Hal ini disebabkan banyak faktor yang berkontribusi terhadap kinerja perusahaan (Siepel, Camerani, \& Masucci, 2019). Begitu juga dengan penelitian yang dilakukan oleh Hilmi, T Ramayah, \& Yanti (2011) dan Rhee, Taekyung, \& Do Hyung (2009) yang juga menyatakan bahwa inovasi tidak berpengaruh terhadap kinerja bisnis.
Berdasarkan paparan di atas dapat dijelaskan bahwa secara umum inovasi memberikan pengaruh pada kinerja bisnis disamping faktor-faktor lainnya seperti faktorfaktor internal ataupun eksternal. Oleh karena itu, penelitian ini bertujuan untuk menganalisis peranan inovasi sebagai pemediasi faktor antara orientasi kewirausahaan dengan kemampuan manajemen. Manfaat secara luas diharapkan penelitian ini dapat memberikan wawasan atau pengetahuan mengenai peran pentingnya faktor inovasi dalam memengaruhi kinerja usaha khususnya pada usaha kecil menengah yang memiliki daya saing dinamis seperti usaha asesoris gawai.

\section{METODE PENELITIAN}

Penelitian ini bersifat deskriptif kuantitatif. Menurut Sugiyono (2016), penelitian deskriptif dapat dijelaskan sebagai bentuk penelitian dengan tujuan untuk mendeskripsikan suatu hal yang pada umumnya terkait dengan karakteristik suatu variabel. Metode ini merupakan metode ilmiah atau scientific karena telah memenuhi kaidah-kaidah ilmiah dimana mempunyai data penelitian berupa angka-angka dan analisis menggunakan statistik. Penelitian ini menggunakan data primer yang langsung didapat dari responden yang memiliki usaha asesoris gawai di ITC Roxy Mas, Jakarta. Teknik pengumpulan data yang digunakan dalam penelitian ini adalah survey dengan menggunakan instrumen kuisioner yang diberikan kepada pemilik atau penanggung jawab usaha asesoris gawai di ITC Roxy Mas, Jakarta yang merupakan populasi dari penelitian ini. Jumlah sampel pada penelitian ini sebanyak 91 responden yang diambil secara insidental sampling. Menurut (Hair, Black, \& Babin, 2010) jumlah sampel dapat ditentukan dengan mengalikan jumlah indikator penelitian dengan 5-10. Oleh karena itu, jumlah sampel tersebut masih memenuhi kriteria penentuan jumlah sampel.

Tabel 2. Pengembangan Instrumen

$\begin{array}{lll}\text { Peubah Definisi } & \text { Indikator }\end{array}$


1. Output penjualan dalam periode tertentu
Kinerja Usaha mana dengan pengorbanan berbagai macam sumber daya

2. Balik modal yang telah dikeluarkan

3. Perolehan laba usaha dalam periode tertentu

4. Usaha yang bertumbuh dalam periode tertentu

1. Inovasi produk yang memiliki daya saing

Proses dan/atau hasil pengembangan

Inovasi pemanfaatan suatu produk/ sumber daya yang telah ada sebelumnya, sehingga memiliki nilai yang lebih berarti.
2. Inovasi proses untuk meningkatkan kualitas

3. Inovasi Administratif

1. Mengambil Risiko

2. Pro-aktif pada peluang yang ada

3. Agresif dalam bersaing
Kewirausahaan

Kemampuan Manajemen
Cerminan dalam mengemukakan sejauh mana sebuah bisnis membangun identifikasi dan memanfaatkan peluang
1. Pengorganisasian

2. Pengendalian

3. Kepemimpinan
Suatu proses yang khas yang terdiri dari perencanaan, pengorganisasian, pengarahan, pengendalian yang dilakukan untuk menentukan serta mencapai sasaran
Penelitian ini menggunakan Partial Least Square (PLS) untuk model Structural Equation Modelling (SEM). Partial Least Square merupakan metode alternative analisis dengan Structural Equation Modelling (SEM). PLS adalah teknik statistika multivariat yang melakukan perbandingan variabel dependen berganda dan variabel independen berganda.

\section{HASIL DAN PEMBAHASAN}

\section{Profil Responden}

Berdasarkan grafik gender, responden pria sebesar 46\% (42 orang), dan wanita sebesar $54 \%$ (49 orang). Maka dapat dikatakan dalam penelitian ini, jenis kelamin yang dominan dalam penelitian ini adalah responden perempuan

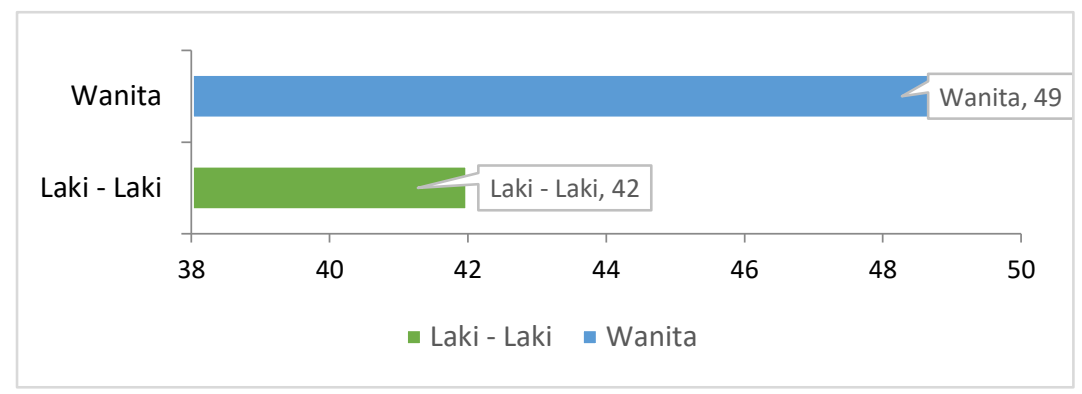

Gambar 1. Gender Responden

Sumber: SMART-PLS 3.0, n=91

Berdasarkan grafik usia, responden terbagi menjadi 3 kategori. Kategori pertama adalah responden dengan umur 30 tahun kebawah dimana persentase dalam kategori ini sebesar 55\% (50 orang). Kategori kedua adalah responden dengan umur 31 sampai 50 tahun dimana persentasenya adalah sebesar 43\% (39 orang). Kategori ketiga adalah responden dengan umur 51 tahun keatas dimana kategori ini tergolong minoritas karena persentasenya hanya sebesar 2\% (2 orang). Maka dapat dikatakan usia yang paling dominan dalam penelitian ini adalah responden dengan usia 3150 tahun. 


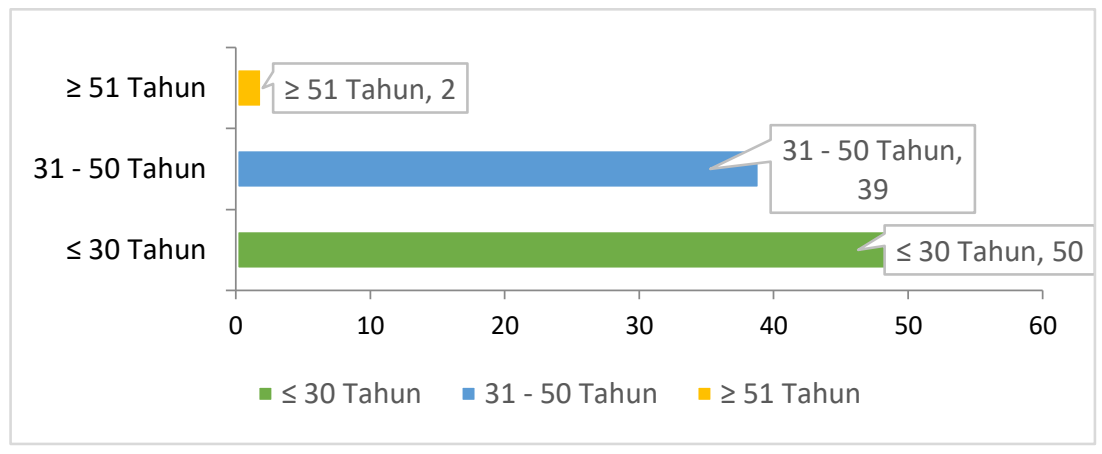

Gambar 2. Usia Responden

Sumber: SMART-PLS 3.0, n=91

Selanjutnya berdasarkan grafik pendapatan, responden dalam penelitian ini dibagi menjadi 2 . Responden dengan pendapatan sebesar $26-$ 209 juta dalam dimasukan kedalam kategori usaha kecil. Sementara responden dengan pendapatan sebesar 210 juta -4 Miliar dimasukan kedalam kategori usaha menengah. Persentase dari kategori usaha kecil dan usaha menengah adalah $65 \%$ (59 orang) untuk usaha kecil dan 35\% (32 orang) untuk usaha menengah. Artinya usaha kecil dalam penelitian ini lebih dominan.

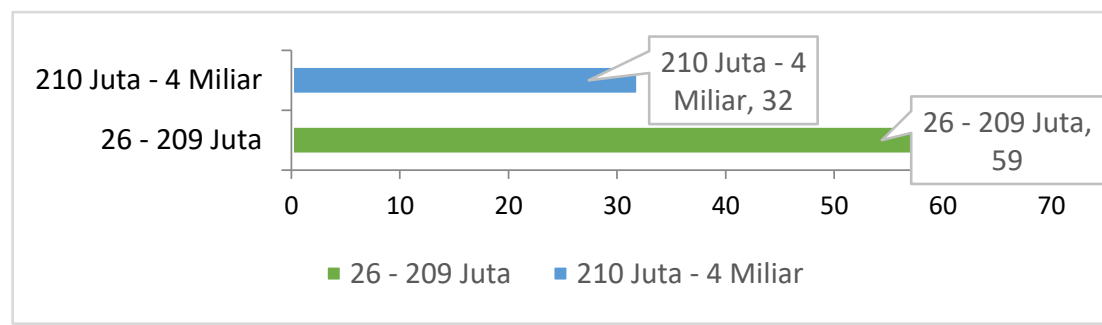

Gambar 3. Pendapatan Usaha Responden

Sumber: SMART-PLS 3.0, $\mathrm{n}=91$

\section{Kesahian \& Kehandalan}

Model PLS Algorithm diatas merupakan model yang telah diolah dimana 2 indikator dari variabel kinerja bisnis telah dihapus yaitu indikator KB3 dan KB4.
Sehingga model PLS Algorithm jika dilihat dari skor jalur dari indikator terhadap variabelnya sudah memenuhi syarat PLS.

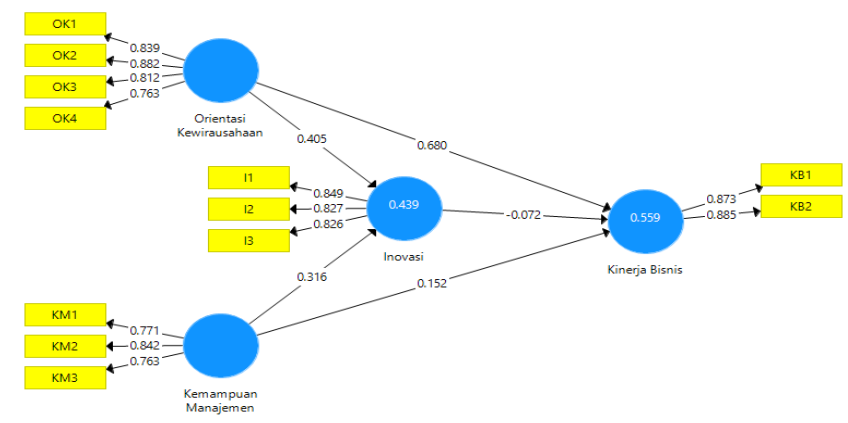

Gambar 4. Model PLS- Algorithm Sumber: SMART-PLS 3.0, $\mathrm{n}=91$ 
Model Bootstrapping diatas merupakan model Bootstrapping yang telah diolah, sehingga dari model diatas tersisa 12 indikator. Model Bootstrapping digunakan untuk melihat pengaruh antar variabel yang dinilai bernilai dari variabel antar dan akan dibahas pada sub bab uji hipotesis

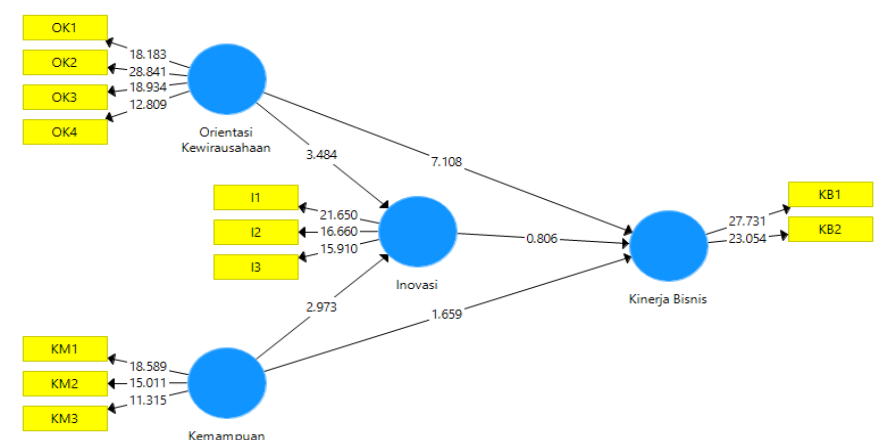

Gambar 5. Model Bootstrapping

Sumber: SMART-PLS 3.0, $\mathrm{n}=91$

Tabel outer loading diatas merupakan tabel yang sudah memenuhi kriteria PLS dimana syarat outer loading untuk memenuhi validitas konvergen adalah nilai outer loading berada diatas 0,7 . Tabel diatas menunjukan bahwa masing-masing indikator sudah memiliki nilai outer loading diatas 0,7 . Oleh karena itu, validitas konvergen apabila dilihat dari outer loading sudah memenuhi syarat.

Tabel 3. Outer Loading

\begin{tabular}{|c|c|c|}
\hline Item & Peubah & Outer loading \\
\hline I1 & \multirow{3}{*}{ Inovasi } & 0.85 \\
\hline $\mathrm{I} 2$ & & 0.83 \\
\hline $\mathrm{I} 3$ & & 0.83 \\
\hline KB1 & \multirow{2}{*}{ Kinerja Bisnis } & 0.87 \\
\hline KB2 & & 0.88 \\
\hline KM1 & \multirow{3}{*}{ Kemampuan Manajemen } & 0.77 \\
\hline KM2 & & 0.84 \\
\hline KM3 & & 0.76 \\
\hline OK1 & \multirow{4}{*}{ Orientasi Kewirausahaan } & 0.84 \\
\hline $\mathrm{OK} 2$ & & 0.88 \\
\hline OK3 & & 0.81 \\
\hline OK4 & & 0.76 \\
\hline
\end{tabular}

Sumber: SMART-PLS 3.0, n=91

Tabel AVE merupakan nilai yang digunakan sebagai cara lain untuk menilai validitas konvergen apakah sudah memenuhi syarat atau belum. Nilai yang disyaratkan agar AVE dapat diterima adalah masing-masing variabel mempunyai nilai diatas 0,5.
Berdasarkan tabel diatas, maka dapat dikatakan bahwa validitas konvergen apabila dilihat dari nilai AVE sudah memenuhi syarat karena keempat variabel diatas sudah memiliki nilai AVE diatas 0,5. 
Tabel 4. Average Variance Extracted (AVE)

\begin{tabular}{ll}
\hline \multicolumn{1}{c}{ Peubah } & $\begin{array}{l}\text { Average Variance Extracted } \\
\text { (AVE) }\end{array}$ \\
\hline Inovasi & 0.70 \\
\hline $\begin{array}{l}\text { Kemampuan } \\
\text { Manajemen }\end{array}$ & 0.63 \\
\hline $\begin{array}{l}\text { Kinerja Bisnis } \\
\text { Orientasi } \\
\text { Kewirausahaan }\end{array}$ & 0.77 \\
\hline \multicolumn{2}{c}{ Sumber: SMART-PLS 3.0, $\mathrm{n}=91$}
\end{tabular}

Hasil cross loadings yang berfungsi sebagai metode untuk melihat apakah validitas diskriminan sudah terpenuhi atau belum. Syarat agar validitas diskriminan terpenuhi adalah nilai cross loadings dari setiap indikator terhadap variabelnya haruslah diatas 0,7 . Dari tabel diatas, dapat dikatakan bahwa data penelitian ini sudah memenuhi syarat validitas diskriminan, karena tabel menunjukan bahwa nilai dari masing-masing indikator terhadap variabelnya mempunyai nilai diatas 0,7 .

Tabel 5. Cross Loadings

\begin{tabular}{lllll}
\hline Item & Inovasi & $\begin{array}{l}\text { Kemampuan } \\
\text { Manajemen }\end{array}$ & $\begin{array}{l}\text { Kinerja } \\
\text { Bisnis }\end{array}$ & $\begin{array}{l}\text { Orientasi } \\
\text { Kewirausahaan }\end{array}$ \\
\hline $\mathrm{I} 1$ & $\underline{0.85}$ & 0.50 & 0.41 & 0.56 \\
\hline $\mathrm{I} 2$ & $\underline{0.83}$ & 0.46 & 0.34 & 0.47 \\
\hline $\mathrm{I} 3$ & $\underline{0.83}$ & 0.51 & 0.35 & 0.51 \\
\hline $\mathrm{KB} 1$ & 0.40 & 0.55 & $\underline{0.87}$ & 0.62 \\
\hline $\mathrm{KB} 2$ & 0.37 & 0.46 & $\underline{0.88}$ & 0.67 \\
\hline $\mathrm{KM} 1$ & 0.52 & $\underline{0.77}$ & 0.45 & 0.56 \\
\hline $\mathrm{KM} 2$ & 0.41 & $\underline{0.84}$ & 0.44 & 0.52 \\
\hline $\mathrm{KM} 3$ & 0.47 & $\underline{0.76}$ & 0.47 & 0.54 \\
\hline OK1 & 0.55 & 0.68 & 0.69 & $\underline{0.84}$ \\
\hline OK2 & 0.49 & 0.56 & 0.61 & $\underline{0.88}$ \\
\hline OK3 & 0.58 & 0.53 & 0.56 & $\underline{0.81}$ \\
\hline OK4 & 0.41 & 0.47 & 0.58 & $\underline{0.76}$ \\
\hline & & Sumber: SMART-PLS 3.0,
\end{tabular}

Hasil di bawah berikut merupakan hasil yang menunjukan penilaian terhadap reliabilitas yang dinilai dari 2 cara, yaitu berdasarkan cronbach's alpha dan berdasarkan composite reliability. Syarat yang diperlukan agar data penelitian dikatakan reliabel adalah nilai dari cronbach's alpha berada diatas 0,7 dan nilai composite reliability berada diatas 0,7 . Maka dapat disimpulkan data dalam penelitian ini sudah reliabel karena tabel menunjukan nilai cronbach's alpha dan composite reliability dari masing-masing variabel mempunyai nilai diatas 0,7 . 
Tabel 6. Composite Reliability

\begin{tabular}{lll}
\hline Peubah & $\begin{array}{l}\text { Cronbach's } \\
\text { Alpha }\end{array}$ & $\begin{array}{l}\text { Composite } \\
\text { Reliability }\end{array}$ \\
\hline Inovasi & 0.78 & 0.87 \\
\hline Kemampuan Manajemen & 0.70 & 0.84 \\
\hline Kinerja Bisnis & 0.71 & 0.87 \\
\hline Orientasi Kewirausahaan & 0.84 & 0.89 \\
\hline
\end{tabular}

Sumber: SMART-PLS 3.0, n=91

Hasil di bawah merupakan nilai yang menunjukan hubungan dari variabel terhadap variabel lainnya. Karena dalam hal ini variabel yang terikatnya adalah kinerja bisnis, maka kolom yang digunakan adalah kinerja bisnis. Dari kolom tersebut dapat terlihat bahwa nilai tertinggi dikontribusikan oleh orientasi kewirausahaan sebesar 0,74. Hal ini menunjukan bahwa dari semua variabel independen yang ada dalam penelitian ini, orientasi kewirausahaan mempunyai pengaruh tertinggi dengan kinerja bisnis. Orientasi kewirausahaan berhubungan dengan kinerja bisnis sebesar $74 \%$.

Tabel 7. Latent Variable Correlations

\begin{tabular}{lllll}
\hline Peubah & Inovasi & $\begin{array}{l}\text { Kemampuan } \\
\text { Manajemen }\end{array}$ & $\begin{array}{l}\text { Kinerja } \\
\text { Bisnis }\end{array}$ & $\begin{array}{l}\text { Orientasi } \\
\text { Kewirausahaan }\end{array}$ \\
\hline Inovasi & 1.00 & 0.59 & 0.44 & 0.62 \\
\hline $\begin{array}{l}\text { Kemampuan } \\
\text { Manajemen }\end{array}$ & 0.59 & 1.00 & 0.58 & 0.68 \\
\hline Kinerja Bisnis & 0.44 & 0.58 & 1.00 & 0.74 \\
\hline $\begin{array}{l}\text { Orientasi } \\
\text { Kewirausahaan }\end{array}$ & 0.62 & 0.68 & 0.74 & 1.00 \\
\hline
\end{tabular}

Sumber: SMART-PLS 3.0, n=91

Hasil di bawah berikut menunjukan seberapa besar variabel-variabel independen dalam penelitian ini dapat menjelaskan variabel dependen yang diteliti. Variabel dependen dalam penelitian ini adalah kinerja bisnis, maka baris yang digunakan pada tabel tersebut adalah baris kinerja bisnis. Dari tabel tersebut, dapat dilihat pada baris kinerja bisnis, ditunjukan nilai 0,56 . Hal ini berarti dalam penelitian ini, orientasi kewirausahaan, kemampuan manajemen, dan inovasi dapat menjelaskan kinerja bisnis sebesar $56 \%$, dan sisanya $44 \%$ dijelaskan oleh variabel lain diluar penelitian. Hal ini jika mengacu pada metode penelitian artinya model dalam penelitian ini bersifat moderate karena nilainya berada di angka 0,50 .

Tabel 8. $R$ Square 


\begin{tabular}{ll}
\hline Peubah & $\boldsymbol{R}$ Square \\
\hline Inovasi & 0.44 \\
\hline Kinerja Bisnis & 0.56 \\
\hline \multicolumn{2}{c}{ Sumber: SMART-PLS 3.0, n=91 }
\end{tabular}

Untuk melihat apakah hipotesis diterima maka dapat melihat nilai T-Statistik, apabila nilai T-Statistik berada diatas 1,96 maka hipotesis diterima dan apabila nilai TStatistik berada dibawah 1,96 maka hipotesis ditolak. Untuk melihat arah pengaruhnya dapat melihat nilai original sample, apabila original sample menunjukan angka negatif, maka pengaruhnya negatif, apabila original sample menunjukan angka positif, maka pengaruhnya positif. Untuk melihat apakah pengaruhnya signifikan atau tidak dapat melihat nilai $\mathrm{P}$ Values, apabila nilai $\mathrm{P}$ Values berada dibawah 0,05 maka pengaruhnya signifikan dan apabila nilai $\mathrm{P}$ Values berada diatas 0,05 maka pengaruhnya tidak signifikan. Berikut adalah uji hipotesis dalam penelitian ini.

Tabel 9. Total Effects

\begin{tabular}{|c|c|c|c|}
\hline & $\begin{array}{l}\text { Original } \\
\text { Sample }(O)\end{array}$ & $\begin{array}{l}\text { T Statistics } \\
(|O / S T D E V|)\end{array}$ & $P$ Values \\
\hline \multicolumn{4}{|l|}{ Efek Langsung } \\
\hline Inovasi -> Kinerja Bisnis & -0.07 & 0.81 & 0.42 \\
\hline Kemampuan Manajemen -> Inovasi & 0.32 & 2.97 & 0.00 \\
\hline $\begin{array}{l}\text { Kemampuan Manajemen -> Kinerja } \\
\text { Bisnis }\end{array}$ & 0.15 & 1.66 & 0.10 \\
\hline Orientasi Kewirausahaan -> Inovasi & 0.41 & 3.48 & 0.00 \\
\hline $\begin{array}{l}\text { Orientasi Kewirausahaan -> Kinerja } \\
\text { Bisnis } \\
\text { Efek Tidak Langsung }\end{array}$ & 0.68 & 7.11 & 0.00 \\
\hline $\begin{array}{l}\text { Kemampuan Manajemen -> Inovasi } \\
\text {-> Kinerja Bisnis }\end{array}$ & -0.02 & 0.75 & 0.45 \\
\hline $\begin{array}{l}\text { Orientasi Kewirausahaan -> Inovasi } \\
\text {-> Kinerja Bisnis }\end{array}$ & -0.03 & 0.75 & 0.46 \\
\hline
\end{tabular}

Sumber: SMART-PLS 3.0, n=91

Berdasarkan nilai dari uji hipotesis, ditunjukan bahwa pengaruh orientasi kewirausahaan terhadap kinerja bisnis memiliki nilai T-Statistik sebesar 7,11 dengan original sample 0,68 dan nilai $\mathrm{P}$ Values sebesar 0,00. Hal ini berarti hipotesis 1 diterima, terdapat pengaruh orientasi kewirausahaan terhadap kinerja bisnis UKM asesoris gawai di ITC Roxy Mas. Dengan nilai original sample yang positif dan $\mathrm{p}$ values sebesar 0,00. Artinya apabila pemilik atau penanggung jawab meningkatkan orientasi kewirausahaan dalam usahanya, akan terjadi peningkatan yang positif dan signifikan dalam kinerja bisnisnya.

Berdasarkan nilai dari uji hipotesis, ditunjukan bahwa pengaruh kemampuan manajemen terhadap kinerja bisnis memiliki nilai T-Statistik sebesar 1,66 dengan original sample 0,15 dan nilai $\mathrm{P}$ Values sebesar 0,10. Hal ini menunjukan bahwa hipotesis 2 ditolak. Tidak terdapat pengaruh kemampuan manajemen terhadap kinerja bisnis pada UKM asesoris gawai di ITC Roxy Mas. Sehingga 
pemilik usaha atau penanggung jawab tidak dapat meningkatkan kinerja bisnisnya meskipun kemampuan manajemennya meningkat.

Nilai dari uji hipotesis, ditunjukan bahwa pengaruh orientasi kewirausahaan terhadap inovasi memiliki nilai T-Statistik sebesar 3,48 dengan original sample 0,41 dan nilai $P$ Values sebesar 0,00 . Hal ini menunjukan bahwa hipotesis 3 diterima. Terdapat pengaruh orientasi kewirausahaan terhadap inovasi pada UKM asesoris gawai di ITC Roxy Mas. Jadi apabila pemilik atau penanggung jawab dapat meningkatkan orientasi kewirausahaan dalam usahanya, maka pengaruhnya adalah meningkatnya inovasi secara positif dan signifikan.

Nilai dari uji hipotesis, ditunjukan bahwa pengaruh kemampuan manajemen terhadap inovasi memiliki nilai T-Statistik sebesar 2,97 dengan original sample 0,32 dan nilai $\mathrm{P}$ Values sebesar 0,00 . Hal ini menunjukan bahwa hipotesis 4 diterima. Terdapat pengaruh kemampuan manajemen terhadap inovasi pada UKM asesoris gawai di ITC Roxy Mas. Sehingga apabila pemilik atau penanggung jawab memiliki kemampuan manajemen yang semakin baik maka inovasi dalam usaha tersebut juga terpengaruh secara positif dan signifikan.

Nilai dari uji hipotesis, ditunjukan bahwa pengaruh inovasi terhadap kinerja bisnis memiliki nilai T-Statistik sebesar 0,81 dengan original sample sebesar $-0,07$ dan nilai $\mathrm{P}$ Values sebesar 0,42. Hal ini menunjukan bahwa hipotesis 5 ditolak. Tidak terdapat pengaruh inovasi terhadap kinerja bisnis UKM asesoris gawai di ITC Roxy Mas. Sehingga jika pemilik atau penanggung jawab ingin meningkatkan kinerja bisnis mereka, inovasi tidak dapat digunakan.

Nilai dari uji hipotesis, ditunjukan bahwa pengaruh orientasi kewirausahaan terhadap kinerja bisnis dengan inovasi sebagai variabel mediasi menunjukan nilai T-Statistik sebesar 0,75 dengan nilai original sample sebesar -0,03 dan $p$ values sebesar 0,46. Sehingga hipotesis 6 ditolak. Tidak terbukti adanya pengaruh orientasi kewirausahaan terhadap kinerja bisnis UKM asesoris gawai ITC Roxy Mas ketika dimediasi oleh inovasi. Hal ini dikarenakan meskipun orientasi kewirausahaan dapat meningkatkan inovasi secara parsial, namun inovasi tidak dapat memberikan pengaruh terhadap kinerja bisnis karena memang dari awal inovasi tidak berperan dalam meningkatkan kinerja bisnis pada UKM asesoris gawai ITC Roxy Mas.

Nilai dari uji hipotesis, ditunjukan bahwa pengaruh kemampuan manajemen terhadap kinerja bisnis dengan inovasi sebagai variabel mediasi menunjukan nilai T-Statistik sebesar 0,75 dengan nilai original sample sebesar -0,02 dan $\mathrm{p}$ values sebesar 0,45. Sehingga hipotesis 7 ditolak. Tidak terbukti adanya pengaruh kemampuan manajemen terhadap kinerja bisnis UKM asesoris gawai ITC Roxy Mas ketika dimediasi oleh inovasi. Hal ini berarti meskipun kemampuan manajemen yang baik dapat meningkatkan inovasi, namun inovasi tersebut tidak mampu untuk mendorong kinerja bisnis dalam UKM asesoris gawai ITC Roxy Mas.

\section{SIMPULAN}

Berdasarkan hasil penelitian dan pembahasan, maka peneliti membentuk kesimpulan yang berkaitan dengan tujuan penelitian yaitu :

1. Orientasi kewirausahaan mempunyai pengaruh terhadap kinerja bisnis pada UKM asesoris gawai di ITC Roxy Mas.

2. Kemampuan manajemen tidak mempunyai pengaruh terhadap kinerja bisnis pada UKM asesoris gawai di ITC Roxy Mas.

3. Orientasi kewirausahaan mempunyai pengaruh terhadap inovasi pada UKM asesoris gawai di ITC Roxy Mas.

4. Kemampuan manajemen mempunyai pengaruh terhadap inovasi pada UKM asesoris gawai di ITC Roxy Mas.

5. Inovasi tidak mempunyai pengaruh terhadap kinerja bisnis pada UKM asesoris gawai di ITC Roxy Mas.

6. Orientasi kewirausahaan yang dimediasi inovasi tidak mempunyai 
pengaruh terhadap kinerja bisnis pada UKM asesoris gawai di ITC Roxy Mas.

7. Kemampuan manajemen yang dimediasi inovasi tidak mempunyai pengaruh terhadap kinerja bisnis pada UKM asesoris gawai di ITC Roxy Mas.

\section{DAFTAR PUSTAKA}

Arago'n-Correa, J. A., Garc1'a-Morales, V. J., \& Cordón-Pozo, E. (2007). Leadership and organizational learning's role on innovation and performance: Lessons from Spain. Industrial Marketing Management, 36, 349 - 359.

Atalay, M., Anafarta, N., \& Sarvan, F. (2013). The relationship between innovation and firm performance: An empirical evidence from Turkish automotive supplier industry. Procedia - Social and Behavioral Sciences, 75, 226 - 235.

Audretsch, D., Coad, A., \& Segara, A. (2014). Firm growth and innovation. Small Business Economics, 43(4), 743-749.

Bhattacharya, M., \& Bloch, H. (2004). Determinants of Innovation. Small Business Economics, 22, 155-162.

Calantone, R. J., Cavusgil, S. T., \& Zhao, Y. (2002). Learning orientation, firm innovation capability, and firm performance. Industrial Marketing Management, 31, 515- 524.

Caseiro, N., \& Coelho, A. (2018). Business Intelligence and Competitiveness: The Mediating Role of Entrepreneurial Orientation. Competitiveness Review: An International Business Journal, 28(2), 213-226.

Coad, A, \& Rao, R. (2008). Innovation and firm growth in high-tech sectors: a quantile regression approach. Research Policy, 37(4), 633-648.

Coad, Alex, Cowling, M., Nightingale, P., Pellegrino, G., Savona, M., \& Siepel, J. (2014). Innovative Firms and Growth. London.

Corrocher, N., \& Zirulia, L. (2010). Demand and innovation in services: The case of mobile communications. Research Policy, 39, 945-955.

Covin, J. G., \& Miller, D. (2014). International Entrepreneurial Orientation: Conceptual Considerations, Research Themes, Measurement Issues, and Future Research Directions. Entrepreneurship Theory and Practice, 38(1), 11-44.

Damanpour, F. (2010). An Integration of Research Findings of Effects of Firm Size and Market Competition on Product and Process Innovations. British Journal of Management, 21, 996-1010.

Dhliwayo, S. (2014). Entrepreneurship and Competitive Strategy: An Integrative Approach. The Journal of Entrepreneurship, 23(1), 115-135.

Goedhuys, M., \& Veugelers, R. (2012). Innovation strategies, process and product innovations and growth: Firm-level evidence from Brazil. Structural Change and Economic Dynamics, 23, 516- 529.

Hair, J. F., Black, W. C., \& Babin, B. J. (2010). Multivariate Data Analysis (7th ed.). New Jersey: Pearson Prentice Hall.

Herath, H. M. ., \& Rosli, M. (2014). Strategic Orientations and SME Performance: Moderating Effect of Absorptive Capacity of the Firm. Asian Social Science, 10(13), 95-107.

Herzog, P., \& Leker, J. (2010). Open and closed innovation - different innovation cultures for different strategies. Int. J. Technology Management, 52(3/4), 322 - 343.

Hilmi, M. F., T Ramayah, \& Yanti, M. (2011). Product and Process Innovativeness: Evidence From Malaysian SMEs. European Journal of Social Sciences, 16(4), 547-555.

Huang, F., \& Rice, J. L. (2009). The role of absorptive capacity in facilitating Open innovation outcomes: A study of Australian SMEs in the manufacturing sector. International Journal of Innovation Management, 13(2), 201-220.

IDC. (2018). 5 Merk Ponsel Ini Rajai Penjualan 
Smartphone di Indonesia. Retrieved February 19, 2020, from kabar.news website: https://kabar.news/5-merkponsel-ini-rajai-penjualan-smartphonedi-indonesia

Jansen, J. J. P., Van Den Bosch, F. A. J., \& Volberda, H. W. (2006). Exploratory Innovation, Exploitative Innovation, and Performance: Effects of Organizational Antecedents and Environmental Moderators. Management Science, 52(11), 1661-1674.

Jayaram, J., Oke, A., \& Prajogo, D. (2014). The antecedents and consequences of product and process innovation strategy implementation in Australian manufacturing firms. International Journal of Production Research, 52(15), 4424-4439.

Jiang, L., Waller, D. S., \& Cai, S. (2013). Does ownership type matter for innovation? Evidence from China. Journal of Business Research, 66, 2473-2478.

Katila, R., \& Shane, S. (2005). When Does Lack of Resources Make New Firms Innovative? The Academy of Management Journal, 48(5), 814-829.

Lumpkin, G. ., \& Dess, G. G. (1996). Clarifying the Entrepreneurial Orientation Construct and Linking It to Performance. The Academy of Management Review, 21(1), 135-172.

Mamduh, N. (2018). Penjualan Ponsel Sepi di ITC Roxy Mas, Ini Tanggapan Apkomindo. Retrieved February 19, 2019, from telset.id website: https://telset.id/234700/penjualan-ponselsepi-di-itc-roxy-mas-ini-tanggapanapkomindo/

Murat Ar, I., \& Baki, B. (2011). Antecedents and performance impacts of product versus process innovation: Empirical evidence from SMEs located in Turkish science and technology parks. European Journal of Innovation Management, 14(2), 172-206.

Nurlina. (2014). The Effect of Management
Capabilities and Entrepreneurship Orientation to Innovation and Implication on Business Performance: Study at Embroidery Motifs SMEs in AcehIndonesia. Journal of Economics and Sustainable Development, 5(26), 57-61.

Oke, A., Projogo, D. I., \& Jayaram, J. (2013). Strengthening the Innovation Chain: The Role of Internal Innovation Climate and Strategic Relationships with Supply Chain Partners. Journal of Supply Chain Management, 49, 43-58.

Prajogo, D. I. (2015). The strategic fit between innovation strategies and business environment in delivering business performance. Intern. Journal of Production Economics, 1-31.

Rhee, J., Taekyung, P., \& Do Hyung, L. (2009). Drivers of Innovativeness and Performance for Innovative SMEs in South Korea: Mediation of Learning Orientation. Journal Technovation, 6575.

Shu, C., Page, A. L., Gao, S., \& Jiang, X. (2012). Managerial Ties and Firm Innovation: Is Knowledge Creation a Missing Link? Journal of Product Innovation Management, 29, 125-143.

Siepel, J., Camerani, R., \& Masucci, M. (2019). Skills combinations and firm performance. Small Bus Econ.

Sugiyono. (2016). Metode Penelitian Kuantitatif, Kualitatif, dan $R$ \& D. Bandung: Alfabeta.

Tao, L., Garnsey, E., Probert, D., \& Ridgman, T. (2010). Innovation as response to emissions legislation: revisiting the automotive catalytic converter at Johnson Matthey. R\&D Management, 40(2), 154168.

Tsai, K.-H., \& Yang, S.-Y. (2013). Firm innovativeness and business performance: The joint moderating effects of market turbulence and competition. Industrial Marketing Management, 42, 1279-1294.

Tuan, N., Nhan, N., Giang, P., \& Ngoc, N. 
(2016). The Effects of Innovation on Firm Performance of Supporting Industries in Hanoi - Vietnam. Journal of Industrial Engineering and Management, 9(2), 413431.

Wiklund, J., \& Shepherd, D. (2003). Knowledge-Based Resources, Entrepreneurial Orientation, and the
Performance of Smalland Medium-Sized Businesses. Strategic Management Journal, 24(1), 1307-1314.

Yalabik, B., \& Fairchild, R. (2011). Customer, regulatory, and competitive pressure as drivers of environmental innovation. Int. J.ProductionEconomics, 131(519-527). 